\title{
SAPS 2 SCORE VALID PARAMETER FOR OUTCOME IN SEVERE INFLUENZA
}

\author{
Cvetanovska Marija ${ }^{1}$, Demiri Ilir $^{1}$, Grozdanovski Krsto ${ }^{1}$, Spasovska Katerina ${ }^{1}$, \\ Cvetanovski Vlatko ${ }^{2}$
}

${ }^{1}$ University Clinic for Infectious Diseases and Febrile Conditions, Faculty of Medicine, Ss. Cyril and Methodius University in Skopje, R. North Macedonia

${ }^{2}$ General Hospital Remedika, Skopje, R. North Macedonia

e-mail: mcvetanovska2001@yahoo.com

\begin{abstract}
The aim of study was to identify the significance of SAPS 2 score admission values on outcome in severe influenza.

Materials and methods: The investigation was prospective, group comparison, conducted at the University Clinic for Infectious Diseases, Skopje in a three-year period. The study included adult patients with severe influenza divided in two groups, survived and deceased. Demographic, clinical and biochemical data were noted on admission. The variables of the univariate analysis that showed a significant difference in terms of the outcome were used for creating multivariate logistic and regression analysis of the outcome as dependent factors. The independent predictors for lethal outcome in severe cases of influenza were identified by using logistic regression.

Results: The study included 87 patients with clinical and laboratory confirmed severe influenza divided in two groups: survived $(n=75)$ and deceased $(n=12)$. The overall mortality was $13.79 \%$. Multivariate analysis conducted on admission identified SAPS II score $(\mathrm{p}=0.048)$ as independent predictor of the outcome in severe influenza. The increase of the SAPS II score in one point increased the chance of death in patients with influenza by $1.2 \%$ $(\mathrm{OR}=1.12$ 95\% CI 1.01-2.976).

Conclusion: In our study the SAPS II score has been identified as an independent variable, which has predicted the outcome in patients with severe influenza on hospital admission. The early identification of the outcome predictors in patients with severe influenza will ensure implementation of adequate medical procedures, and also, it will contribute to decreasing the mortality of this disease.
\end{abstract}

Keywords: severe influenza, SAPS II score

\section{Introduction}

Clinical manifestations of influenza range from relatively mild and self-limiting respiratory infections to severe clinical manifestations with significant morbidity and mortality [1]. During seasonal epidemics from 3 to 5 million severe cases and about 250,000-500,000 lethal cases are registered worldwide [2]. Until now there has not been a laboratory test which has served as a potential marker for identification of patients with a high risk of developing severe clinical forms of influenza and lethal outcome [3, 4]. It is known that patients with 
different comorbid conditions such as diabetes mellitus, chronic cardiovascular and pulmonary diseases, immunosuppressive conditions, adult patients and other conditions are at higher risk of developing severe clinical course of the disease and lethal outcome [5]. Although the influenza virus is primarily a respiratory pathogen, the severe clinical forms of the disease are manifested as systemic infections with multisystem organ affection, and even 10-30\% of the diseased need intensive treatment [6, 7]. Pneumonia, delayed antiviral treatment, severe hypoxemia and multisystem organ failure are most commonly referred as leading risk factors for lethal outcome [8].

The largest number of studies has evaluated isolated risk factors leading to lethal outcome and only a few of them have been focused on the complete palette of predictors for development of a severe form of the disease and lethal outcome [9-16]. From the clinical practice point of view, the awareness/recognition of the risk factors and predictors for lethal outcome of influenza is of particular importance in bringing timely and exact decision for hospitalization, treatment or undertaking special measures for intensive monitoring of these patients.

\section{Materials and methods}

The study was prospective, clinical, and was conducted at the University Clinic for Infectious Diseases and Febrile Conditions during a period of three years. It was designed in accordance with the ethics principles of the Declaration of Helsinki for patients and their rights, and was approved by the Ethics Committee of the Faculty of Medicine at Ss. Cyril and Methodius University in Skopje. The study analyzed 87 adult patients ( $\geq 16$ years of age) with clinically and laboratory confirmed severe influenza, divided into two groups based on the outcomes: 75 patients who survived and 12 patients who had lethal outcome. Criteria for inclusion in the study: all patients with clinical and laboratory confirmed severe form of influenza and age $\geq 16$ years. Patients were excluded if they died in the first 24 hours of their inclusion in the study and those who did not receive approval for inclusion. Patients with severe influenza were defined as patients with a clinically and laboratory confirmed influenza who met the criteria for severe influenza: signs of respiratory weakness (dyspnea, tachypnea, hypoxia, cyanosis) such as arterial $\mathrm{PaO} 2<70 \mathrm{mmHg}(<9.0 \mathrm{KPa})$ and/or the need for mechanical ventilation and/or signs of ARDS $\left(\mathrm{PaO}_{2} 2 / \mathrm{FiO}_{2} \leq 200\right)$, the need for intensive care, exacerbation of an existing chronic illness. On admission of patients, the following parameters were noted: demographic characteristics, comorbidities, clinical signs of the disease and laboratory-biochemical characteristics. In order to objectify the severity of the disease and to predict mortality in patients with severe influenza, the simplified acute physiological index (Simplified Acute Physiology Score II-SAPS II) was calculated in the first 24 hours. The SAPS II index was calculated from points obtained by age, body temperature, pulse, diuresis, serum urea concentration, leukocyte count, serum potassium concentration, sodium, bicarbonate, bilirubin concentration, Glasgow coma scale, presence of AIDS, hematological malignancy, and metastatic cancer [17]. If the patient has a SAPS II index of 0.43, the predicted risk of death is $43 \%$. The used variables and points of the SAPS II score are shown in Table 1.

\section{Results}

Out of the 87 patients with severe influenza, 12 patients died and the mortality rate in our study group was $13.79 \%$. Our results showed that women died insignificantly more often than men $(16.13 \%$ vs $12.5 \%$ ( $\mathrm{p}=0.64)$. The age had significant influence on the disease outcome $(\mathrm{p}=0.019)$. The mean age of the deceased patients was $65.58 \pm 17.5$ years, opposite to the mean age of survived patients which was $53.04 \pm 16.8$ years. The results of our study have demonstrated that patients with comorbid conditions died more often than those without these diseases 
$(15.38 \%$ vs $9.09 \%)(\mathrm{p}=0.72)$, but only cardiovascular diseases had a significant impact on the outcome of severe influenza $(\mathrm{p}=0.011)$.

The mean body temperature was slightly different between the group of surviving and deceased patients on admission The average body temperature of $38.04 \pm 1.3^{\circ} \mathrm{C}$ was measured in the group of the deceased, and $38.24 \pm 0.9^{\circ} \mathrm{C}$ in the group of survivors. The mean value of the admission pulse was statistically significantly higher in the group of deceased patients (104.58 \pm 25.2 vs $92.81 \pm 13.8),(\mathrm{p}=0.018)$. Mean arterial pressure had an insignificantly different mean value between the group of survivors and the group of deceased subjects. Death patients had a significantly higher admission respiration rate than survivors ( $\mathrm{p} 0.029)$. The SAPS 2 score measured on admission showed a significantly higher value in the group of deceased patients $(53.4 \pm 24$ vs 33.7 \pm 28.9$)$, $(\mathrm{p}=0.00038)$.

Table 1. Average values of body temperature, pulse, MAP, respiration and SAPS II score on admission in terms of outcome

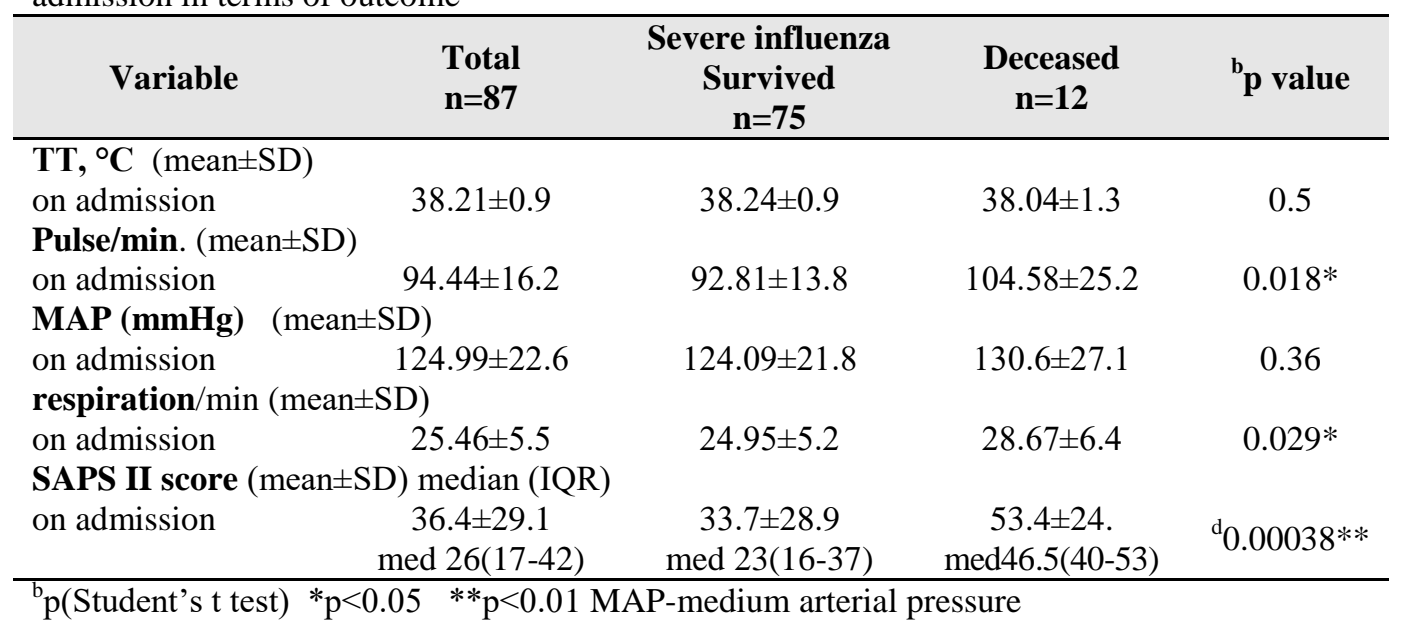

Table 2. Univariate logistic regression analysis for prediction of lethal outcome in patients with influenza

\begin{tabular}{lcc}
\hline \multicolumn{1}{c}{ Variable } & $\begin{array}{c}\text { Crude OR } \\
\text { 95\% CI for OR }\end{array}$ & p value \\
\hline Clinical variables & & \\
temperature $>37.8^{\circ}$ & $0.364(0.105-1.259)$ & 0.11 \\
pulse $>80$ & $1.313(0.149-11.555)$ & 0.806 \\
MAP $<120$ & $0.8(0.076-8.474)$ & 0.853 \\
MAP $>120$ & $1.077(0.112-10.369)$ & 0.949 \\
respiration $>20$ & $1.25(0.247-6.318)$ & 0.787 \\
SAPS II score & $\mathbf{1 . 1 5 ( 1 . 0 7 - 3 . 1 8 )}$ & $\mathbf{0 . 0 3 9} *$ \\
\hline
\end{tabular}

Variables that were significantly associated with death in the univariate logistic regression analysis were included in the multivariate logistic regression analysis to determine independent lethal outcome predictors of influenza.

The results of this analysis confirmed the SAPS II index $(\mathrm{p}=0.048)$ as an independent predictor of lethal outcome. Increasing the SAPS II index by one score increases the chance of death in patients with influenza by $1.2 \%(\mathrm{OR}=1.1295 \% \mathrm{CI} 1.01-2.976)$. 
Table 3. Multivariate logistic regression analysis for prediction of lethal outcome in patients with influenza

\begin{tabular}{ccc}
\hline Variable & $\begin{array}{c}\text { Adjusted OR } \\
\mathbf{9 5 \%} \text { CI for OR }\end{array}$ & p value \\
\hline SAPS II score & $1.12(1.01-2.976)$ & $0.048^{*}$ \\
\hline
\end{tabular}

\section{Discussion}

The mortality rate of the hospitalized patients with severe influenza infection amounted to $13.79 \%$ in our study. The percentage of lethality varies among published studies and it ranges from $10 \%$ to extreme $59 \%$, which certainly depends on the various conditions and criteria according to which patients are analyzed as well as on the criteria for admission to intensive care units [18-20]. Thus, a study performed in China showed that from 60 patients with severe form of influenza $44 \%$ were treated at an intensive care unit and the lethality was $14.7 \%$ [21]. There was no significant difference regarding the mortality between male and female patients in our study, although in most of the studies the male sex was identified as a risk factor associated with lethal outcome $[22,23]$. Our results have demonstrated that from the total number of 12 lethal outcomes, 5 or $(16.1 \%)$ were women and $7(12.5 \%)$ were men. Our study is similar to that conducted in Canada where from the total number of 29 lethal outcomes, $27.6 \%$ were men, whereas $72.4 \%$ were women [22]. The age had significant influence on the disease outcome in our study. The mean age of patients that died was 65.58 years $(\mathrm{p}=0.019)$. The mortality was the highest in patients at the age over $65(27.2 \%)$. These results coincide with almost all studies in the world that identify the old age as an important risk factor for mortality in patients with influenza [23, 24]. All 87 patients with severe influenza in our study had a higher body temperature than $37.8^{\circ} \mathrm{C}$. The mean body temperature between the group of survived and deceased patients showed no statistically significant correlation $(38.7 \pm 0.7$ vs 38.4+0.8) ( $\mathrm{p}=\mathrm{ns})$. The absence of fever in the other patients is due to receiving antipyretic therapy at the initial clinical presentation which does not rule out the presence of influenza $[25,26]$. The other clinical symptoms that were analyzed on admission were medium arterial pressure, pulse, and respiration. The mean value of the admission pulse was statistically significantly higher in the group of deceased patients (104.58 $\pm 25.2 \mathrm{vs}$ $92.81 \pm 13.8),(\mathrm{p}=0.018)$. The mean arterial pressure had an insignificantly different mean value between the group of survivors and the group of deceased subjects. Our deceased patients had a significantly higher admission respiration rate than survivors $(p=0.029)$. The main goal of our study was the SAPS score and its importance in predicting outcome in patients with severe influenza. The SAPS 2 score measured on admission showed a significantly higher value in the group of deceased patients $53.4 \pm 24$ vs $33.7 \pm 28.9(\mathrm{p}=0.00038)$. The SAPS II score in this comparative analysis stood out as an independent predictor of mortality in patients with severe influenza ( $\mathrm{p}=0.00058$ ). This score together with other predictive scores is highly sensitive for lethal outcome prediction which is why it has been examined and referred to as a significant predictor of lethal outcome in world studies [27-29].

\section{Conclusion}

In our study the SAPS II score have been identified as an independent variable, which have predicted the outcome in patients with severe influenza on the very admission. The early identification of the outcome predictors in patients with severe influenza will ensure implementation of adequate medical procedures, and also, it will contribute to decreasing the mortality of this disease. 
Conflict of interest statement. None declared.

\section{References}

1. Thompson WW, Moore MR, Weintraub E Cheng PY, Jin X, Bridges CB, Bresee JS, Shay DK. Estimating Influenza-Associated Deaths in the United States. Am J Public Health 2009; 99(2): 225-30.

2. Young SJ, Hee JC, Heung JW, Seong-Heon W, JinSoo L, Moon-Hyun C, et al. Immunogenicity and Safety of Trivalent Inactivated Influenza Vaccine: A Randomized, Double-Blind, Multi-Center, Phase 3 Clinical Trial in a Vaccine-Limited Country. $J$ Korean Med Sci 2011; 26(2): 191-5.

3. Zimmerman O, Rogowski O, Aviram G, Mizrahi M, Zeltser D, Justo D, et al. Creactive protein serum levels as an early predictor of outcome in patients with pandemic H1N1 influenza A virus infection. BMC Infect Dis 2010; 10: 288.

4. Blyth CC, Iredell JR, Dwyer DE. Rapid-test sensitivity for novel swine-origin influenza A (H1N1) virus in humans. N Engl J Med 2009; 361(25): 2493.

5. Kalyani1 D, Srikanth Bhatt S, Chitralekha T, Rajarao M, Shankar K. Comorbidities in H1N1 Positive Patients-Hospital Based Study, IOSR. J Dental Med Sci 2016; 15: 52-5.

6. Oh WS, Lee SJ, Lee CS, Hur JA, Hur AC, Park YS, et al. A prediction rule to identify severe cases among adult patients hospitalized with pandemic influenza A (H1N1) 2009. J Korean Med Sci 2011; 26(4): 499-506.

7. Mata-Marín LA, Mata-Marín JA, Vásquez-Mota VC, Arroyo-Anduiza CI, GaytánMartínez JE, Manjarrez-Téllez B, et al. Risk factors associated with mortality in patients infected with influenza A/H1N1 in Mexico. BMC Res Notes 2015; 8: 432.

8. Woo HC, Yun SK, Doo SJ, Ji EK, Kun IK, Hee YS, et al. Outcome of pandemic H1N1 pneumonia: clinical and radiological findings for severity assessment. Korean J Intern Med 2011; 26: 160-7.

9. Liu L, Zhang RF, Lu HZ, Lu SH, Huang Q, Xiong YY, Xi XH, Zhang ZY. Sixty-two severe and critical patients with 2009 influenza A (H1N1) in Shanghai, China. Chin Med J (Engl) 2011; 124(11): 1662-6.

10. Yokota RT, Skalinski LM, Igansi CN, de Souza LR, Iser BP, Reis PO, et al. Risk factors for death from pandemic (H1N1) 2009, southern Brazil. Emerg Infect Dis 2011; 17(8): 1467-71.

11. Li G, Yilmaz M, Kojicic M, Fernández-Pérez E, Wahab R, Charles Huskins W, et al. Outcome of critically ill patients with influenza virus infection. J Clin Virol 2009; 46 (3): 275-8.

12. Thompson WW, Shay DK, Weintraub E, et al. Influenza-associated hospitalizations in the United States. JAMA 2004; 292: 1333-40.

13. Sarda C, Palma P, Rello J. Severe influenza: overview in critically ill patients. Curr Opin Crit Care 2019; 25(5): 449-57.

14. Hsu JC, Lee IK, Huang WC, Chen YC, Tsai CY. Clinical Characteristics and Predictors of Mortality in Critically Ill Influenza Adult Patients. J Clin Med 2020; 9(4): 1073.

15. Smith BJ, Price DJ, Johnson D, Garbutt B, Thompson M, Irving LB, Putland M, Tong SYC. Influenza With and Without Fever: Clinical Predictors and Impact on Outcomes in Patients Requiring Hospitalization. Open Forum Infect Dis 2020; 7(7): ofaa268. doi: 10.1093/ofid/ofaa268. 
16. Bouneb R, Mellouli M, Bensoltane H, Baroudi J, Chouchene I, Boussarsar M. Characteristics and outcome of ill critical patients with influenza A infection. Pan Afr Med J 2018; 29: 174. doi: 10.11604/pamj.2018.29.174.13098.

17. Le Gall, JR, Lemeshow, S, Saulnier, F. A new simplified acute physiology score (SAPS II) based on a European/North American multicenter study. JAMA 1993; 270: 2957-63.

18. Louie JK, Acosta M, Winter K, Jean C, Gavali S, Schechter R, et al. California Pandemic (H1N1) Working Group. Factors associated with death or hospitalization due to pandemic 2009 influenza A(H1N1) infection in California. JAMA 2009; 302(17): 1896-902. doi: 10.1001/jama.2009.1583.

19. BinSaeed AA. Characteristics of pandemic influenza A (H1N1) infection in patients presenting to a university hospital in Riyadh, Saudi Arabia. Ann Saudi Med 2010; 30(1):59-62.

20. Domínguez-Cherit G, Lapinsky SE, Macias AE, Pinto R, Espinosa-Perez L, de la Torre A, et al. Critically Ill patients with 2009 influenza A(H1N1) in Mexico. JAMA 2009; 302(17): 1880-7. doi: 10.1001/jama.2009.1536.

21. Cui W, Zhao H, Lu X, Wen Y, Zhou Y, Deng B, et al. Factors associated with death in hospitalized pneumonia patients with 2009 H1N1 influenza in Shenyang, China. BMC Infect Dis 2010; 10:145. doi: 10.1186/1471-2334-10-145.

22. Kumar A, Zarychanski R, Pinto R, Cook D, Marshall J, Lacroix J, et al. Critically ill patients with 2009 influenza A (H1N1) infection in Canada. JAMA 2009; 302:1872-9.

23. Cao B, Li XW, Mao Y, Wang J, Lu HZ, Chen YS, et al. Clinical features of the initial cases of 2009 pandemic influenza A (H1N1) virus infection in China. $N$ Engl J Med 2009; 361: 2507-17.

24. Chen KF, Gaydos C, Rothman RE. Update on emerging infections: news from the Centers for Disease Control and Prevention. Hospitalized patients with novel influenza A (H1N1) virus infection - California, April-May, 2009. Ann Emerg Med 2009; 54(5): 732-6.

25. Loubet P, Samih-Lenzi N, Galtier F, Vanhems P, Loulergue P, Duval X, et al. Factors associated with poor outcomes among adults hospitalized for influenza in France: A three-year prospective multicenter study. J Clin Virol 2016; 79: 68-73.

26. Leung CH, Tseng HK, Wang WS, Chiang HT, Wu AY, Liu CP. Clinical characteristics of children and adults hospitalized for influenza virus infection. J Microbiol Immunol Infect 2014; 47(6): 518-25.

27. Damak H, Chtara K, Bahloul M, Kallel H, Chaari A, Ksibi H, et al. Clinical features, complications and mortality in critically ill patients with 2009 influenza $\mathrm{A}(\mathrm{H} 1 \mathrm{~N} 1)$ in Sfax, Tunisia. Influenza Other Respir Viruses 2011; 5(4): 230-40.

28. Jansen D, Van den Berg R, Bosman G, et al. Influenza A or B virus infection 20122013: incidence, characteristics and outcome in critically ill patients in two Dutch intensive care units. Neth J Crit Care 2014; 18: 11-4.

29. Godinjak A, Iglica A, Rama A, Tančica I, Jusufović S, Ajanović A, et al. Predictive value of SAPS II and APACHE II scoring systems for patient outcome in a medical intensive care unit. Acta Med Acad 2016; 45(2):97-103. doi: 10.5644/ama2006-124.165. 